\title{
Preface to the Special Issue on Child and Adolescent Attachment
}

\author{
Joanna E. Bettmann • Donna D. Friedman
}

Published online: 26 January 2010

(C) Springer Science+Business Media, LLC 2010

\begin{abstract}
The implications of John Bowlby's attachment theory resound through the mental health community. While we know now that much of what Bowlby posited was true, we are still discovering the value of such findings for our clinical work with children and adolescents. Our special issue in Clinical Social Work Journal explores how attachment theory is being used in clinical settings throughout the country. It presents articles relevant to work with infants and toddlers, children and adolescents and families. How can we translate what we know about attachment theory and research into practice? Our special issue authors have attempted to answer this question.
\end{abstract}

\section{Introduction to the Special Issue on Child and Adolescent Attachment}

Attachment theory was founded on the notion that childhood relational experiences create lasting impacts on our expectations for future relationships, emotion regulation and even general mental health. Bowlby believed that humans' needs for relationships were instinctual and survival-driven (Bowlby 1958). Considering other research and other species, Bowlby concluded that we need our mothers, our primary caregiver, without whom we will die.

\footnotetext{
J. E. Bettmann

College of Social Work, University of Utah, Salt Lake City, UT, USA

e-mail: joanna.bettmann@ socwk.utah.edu

D. D. Friedman $(\bowtie)$

Silver School of Social Work, New York University, New York, NY, USA

e-mail: donnademetrif@msn.com
}

He conceptualized that infant crying, suckling and clinging cemented the child's tie to the mother (Bowlby 1958).

Bowlby also made assertions about what happened to children who lacked empathic caregivers. In "Forty-Four Juvenile Thieves: Their Characters and Home-Life", Bowlby (1944) argued that maternal attitudes toward their children - both conscious and unconscious-impacted the child's development: “...in several cases sympathetic discussions with the mothers of the children revealed that their apparent love for their child was only one aspect of their feelings for him. Often an intense, though perhaps unadmitted, dislike and rejection of him also came to light" (p. 20). He drew links between those maternal feelings and children's delinquency. He also posited that children's emotional traumas "mean far more to children than most grown-ups conceive possible" (Bowlby, p. 20). Bowlby's declarations about impacts of caregivers and trauma on children was novel and added significantly to the prevailing dialogue on the mental health of children.

Where children were once thought to be simply resilient blank slates, Bowlby encouraged practitioners to see children as organizing themselves around their caregivers in such a way that huge destruction to children's personalities was possible if stable, available, empathic caregivers were not there. Bowlby created a theory which allowed practitioners to see children's wounds more clearly. His work, along with the video contributions of James and Joyce Robertson, made visible the impacts of problematic caregiving on our child populations.

The implications of Bowlby's ideas continue to resound through the mental health community. The years since have yielded ground-breaking research defining attachment types (Ainsworth et al. 1978), exploring the longitudinal stability of such types (Hamilton 2000; Grossman et al. 2005; Waters et al. 2000; Weinfield et al. 2004) and the 
implications of such findings for clinical settings (Sable 2000; Slade 2008; Wallin 2007). While we know now that much of Bowlby posited was true, we are still discovering the value of such findings for our clinical work with children and adolescents. Our special issue in Clinical Social Work Journal explores how attachment theory is being used in clinical settings throughout the country. It presents articles relevant to work with infants and toddlers, children and adolescents. How can we translate what we know about attachment theory and research into practice? Our special issue authors have attempted to answer this question.

Douglas Goldsmith offers us a brief introduction to clinical work with children based on attachment principles. Reviewing both the attachment principles critical to clinical work as well as current research, Goldsmith effectively bridges a gap between attachment principles, attachment research and practice. He makes clear how attachmentbased work looks and how it links to both theory and research.

Next, co-editor Donna Friedman, along with Beatrice Beebe, Joseph Jaffe and Don Ross, present a study of the microanalysis of infant vocal quality and its relationship to maternal depression. Carefully analyzing videotapes of four-month old infants and their mothers, the author found that infants of depressed mothers were more vocally activated and dysregulated than infants of non-depressed mothers. They present implications of such findings for clinical work, clearly drawing a link between complex emotion regulation research and attachment principles in practice.

Another article addressing infant attachment in our special issue is Beatrice Beebe's award-winning work on the link between mother-infant research and mother-infant treatment. Originally published in the Psychoanalytic Study of the Child in 2005, the article is reprinted here as it makes a critical link for clinical social workers working with mothers and children: how can we use what we know about mothers and babies from research as we practice with this population? Beebe's article makes these difficult links clear.

Suzi Tortora's contribution on non-verbal clinical work with toddlers based in attachment principles adds significantly to our special issue by illustrating how an understanding of non-verbal attachment behaviors translates to practice. Incorporating rich clinical examples, Tortora's work offers a window into attachment-based work with toddlers and parents.

Stubenbort, Cohen and Trybalski contribute an article to this special issue which evaluates an attachment-focused treatment model, a therapeutic preschool for abused children. This article importantly illuminates clearly how attachment principles manifest in practice in a preschool treatment setting.
Two articles in our special issue address clinical work with latency-aged children. The first of these is by Geoff Goodman. His contribution presents important guidelines for developing attachment-based interventions with prepubertal children and explores the impact of parent, child, and therapist characteristics, particularly mental representations, on the potential intervention points of entry being targeted. The second article on latency-aged children is by Zilberstein and Messer, who present current attachment research and thinking regarding disorganized attachment in children. They then use this literature to frame a treatment approach for latency-aged children with disorganized attachment and present a case example which illustrates their unique approach.

Two contributions in this issue speak to attachmentfocused work with adolescents. Co-Editor Joanna Bettmann, along with author Rachael Jasperson, contribute a work which integrates attachment theory and recent neurobiological research. They argue for the importance of integrating physiological understanding into clinical work. They then illustrate the application of attachment theory and neurobiology in treatment through the case example of an adolescent client with panic disorder treated in an outpatient setting. The second article addressing adolescent populations is by Richard Wampler and Adam Downs. Their contribution examines parent and peer attachment in an African American and Latino adolescent male population mandated to attend an alternative school. They explored the relationship between attachment and juvenile delinquency, concluding that attachment cluster membership ("isolating", "disconnected" and "connected") predicted differences in reported violent behaviors, felonies, and theft. They also present the clinical implications of such findings for those working with adolescent populations.

Finally, several articles in our special issue address attachment-based clinical work with families. The first of these is by Howard Steele, Anne Murphy and Miriam Steele. They contribute a work describing an attachmentbased group treatment for stressed and traumatized families. Their article frames the treatment in terms of attachment principles and research, incorporating lengthy clinical examples which illustrate the therapeutic action of the treatment. The second of the family treatment articles comes from Jane Wimmer and Elizabeth Vonk who present a qualitative study of mothers who received attachmentbased family treatment for families with a Reactive Attachment Disordered child. The authors explore the mothers' perception of treatment, aiming to both describe fully an attachment-focused family treatment as well as participants' reactions to it.

The third article in this group comes from Allison Werner-Lin, Nancee Biank and Betsy Rubenstein who 
describe attachment-oriented interventions for children dealing with attachment disruptions following parental death to cancer. The authors frame their treatment in terms of existing attachment research and use two length case examples to illustrate their interventions.

The contributions to this special issue address attachment-focused treatment with infants, toddlers, children, adolescents and their family members. These articles as a group represent both qualitative and quantitative approaches, including research as well as clinical case examples to illustrate approaches. This special issue aims to highlight how attachment theory and research informs emerging practice approaches. The issue aims to be useful to clinical social workers working with difficult, traumatized or stressed children and their families. Attachment principles are as useful to understanding populations in pain now as they were when Bowlby proposed his notions in "FortyFour Juvenile Thieves" so many years ago. The novel approaches represented in this special issue should serve as both inspiration and guide to clinical social workers in integrating attachment into practice.

\section{References}

Ainsworth, M. D. S., Blehar, M. C., Waters, E., \& Wall, S. (1978). Patterns of attachment: A psychological study of the strange situation. Hillsdale, NJ: Erlbaum.
Bowlby, J. (1944/1946). Forty-four juvenile thieves: Their characters and home-life. International Journal of Psycho-analysis, 25, 1953. Reprinted as monograph. London: Bailiere, Tindall and Cox.

Bowlby, J. (1958). The nature of the child's tie to the mother. International Journal of Psycho-Analysis, 39, 350-373.

Grossman, K. E., Grossman, K., \& Water, E. (Eds.). (2005). Attachment from infancy to adulthood: The major longitudinal studies. New York: The Guilford Press.

Hamilton, C. E. (2000). Continuity and discontinuity of attachment from infancy through adolescence. Child Development, 71(3), 690-694.

Sable, P. (2000). Attachment and adult psychotherapy. Northvale, NJ: Jason Aronson Press.

Slade, A. (2008). The implications of attachment theory and research for adult psychotherapy: Research and clinical perspectives. In J. Cassidy \& P. R. Shaver (Eds.), Handbook of attachment: Theory, research and clinical applications (pp. 762-782). NY: The Guilford Press.

Wallin, D. J. (2007). Attachment in psychotherapy. NY: The Guilford Press.

Waters, E., Hamilton, C. E., \& Weinfield, N. S. (2000). The stability of attachment security from infancy to adolescence and early adulthood: General introduction. Child Development, 71(3), 678-683.

Weinfield, N. S., Whaley, G. J. L., \& Egeland, B. (2004). Continuity, discontinuity, and coherence in attachment from infancy to late adolescence: Sequelae of organization and disorganization. Attachment and Human Development, 6(1), 73-97. 